Pecvnia, Monográfico (2009), pp. 155-187

\title{
Los pasivos financieros. Problemática contable de los débitos y partidas a pagar
}

\author{
Raquel Flórez López \\ raquel.florez@unileon.es \\ Universidad de León \\ Fac. de Ciencias Económicas y Empresariales \\ Campus de Vegazana, s/n \\ 24071 León (España)
}

\section{DEFINICIÓN Y CLASIFICACIÓN DE LOS PASIVOS FINANCIEROS}

Los pasivos financieros constituyen una categoría específica de instrumentos financieros regulada en la norma de registro y valoración $\mathrm{n}^{\circ} 9$ "Instrumentos financieros" del NPGC y, de forma más simplificada, en la norma de registro y valoración $n^{\circ} 9$, del mismo título, recogida en el Plan General de Contabilidad para Pequeñas y Medianas Empresas (NPPYMES). De acuerdo con el NPGC, un instrumento financiero es un contrato que da lugar a un activo financiero en una empresa $\mathrm{y}$, simultáneamente, a un pasivo financiero o a un instrumento de patrimonio en otra empresa ${ }^{1}$. La

En esta definición se incluyen los instrumentos derivados, cuyo valor varía en respuesta a los cambios de una variable subyacente especificada en el contrato: tipo de interés, cotización de una divisa, precio de una materia prima cotizada, etc.). 
definición de instrumentos financieros incluye tres categorías principales de elementos patrimoniales con un tratamiento contable muy distinto (Figura 1):

- Los activos financieros, que contienen los elementos patrimoniales líquidos y los derechos de cobro de la empresa frente a terceros; p.e.: efectivo, créditos comerciales, créditos financieros, valores de renta fija adquiridos, inversiones en valores de renta variable de otras empresas, fianzas y depósitos constituidos, desembolsos exigidos a los accionistas.

- Los pasivos financieros, referentes a las obligaciones de pago de la empresa frente a terceros; p.e.: débitos comerciales, deudas con entidades de crédito, valores de renta fija emitidos, otras deudas financieras, fianzas y depósitos recibidos, desembolsos exigidos por terceros sobre participaciones.

- Los instrumentos de patrimonio, que incluyen los títulos o derechos de propiedad que emite la empresa a favor de terceros; p.e.: acciones ordinarias emitidas.

Figura 1. Clasificación de los instrumentos financieros

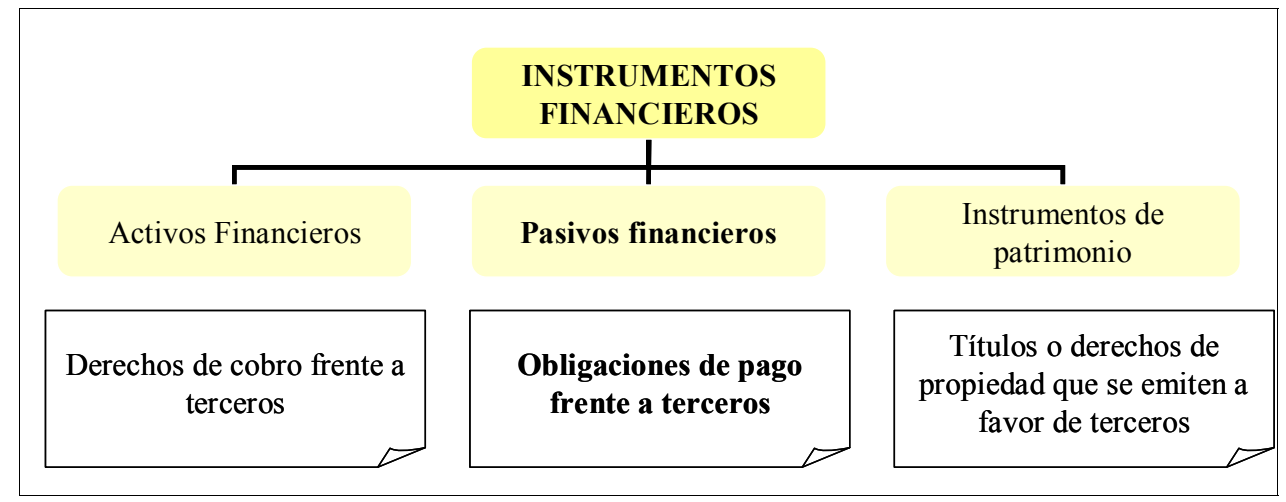

La clasificación de un instrumento financiero dentro de un grupo u otro depende no sólo de su forma jurídica sino de su naturaleza económica, al aplicarse el principio del fondo sobre la forma recogido en el Marco Conceptual del NPGC. Así, por ejemplo, la emisión de acciones rescatables a voluntad del tenedor se clasificará como un pasivo financiero en lugar de un instrumento de patrimonio, al representar una obligación financiera con el adquirente, que puede ejecutarla en cualquier momento. 
Centrando la atención en los pasivos financieros, éstos aparecen definidos en la Norma de Registro y Valoración $n^{\circ} 9$ "Instrumentos financieros", apartado 3:

Los instrumentos financieros se clasificarán como pasivos financieros, en su totalidad o en una de sus partes, siempre que, de acuerdo con su realidad económica, supongan para la empresa una obligación contractual, directa o indirecta, de entregar efectivo u otro activo financiero, o de intercambiar activos o pasivos financieros con terceros en condiciones potencialmente desfavorables (...). También se clasificará como un pasivo financiero, todo contrato que pueda ser, o será, liquidado con los instrumentos de patrimonio propio de la empresa, siempre que:

a) Si no es un derivado, obligue, o pueda obligar, a entregar una cantidad variable de sus instrumentos de patrimonio propio.

b) $\mathrm{Si}$ es un derivado, pueda ser, o será, liquidado mediante una forma distinta al intercambio de una cantidad fija de efectivo o de otro activo financiero por una cantidad fija de los instrumentos de patrimonio de la empresa ${ }^{2}$.

Esta compleja definición aconseja la clasificación de los pasivos financieros según distintos criterios que aclaren su contenido y faciliten su contabilización: (1) en función de su naturaleza y (2) en función del criterio de valoración aplicable.

\subsection{Clasificación de los pasivos financieros según su}

naturaleza

La introducción de la norma de registro y valoración $\mathrm{n}^{\circ} 9$ del NPGC incluye una clasificación de los pasivos financieros según su naturaleza, que incluye las siguientes categorías principales:

- Debitos por operaciones comerciales: proveedores y acreedores varios.

- Deudas con entidades de crédito: préstamos, descuento de efectos, parte dispuesta de las pólizas de crédito, etc.

2 No se incluirán entre los elementos de patrimonio propio aquellos que sean, en sí mismos, contratos para la futura recepción o entrega de instrumentos de patrimonio propio de la empresa. 
- Obligaciones y otros valores negociables emitidos: bonos, pagarés, etc.

- Derivados con valoración desfavorable para la empresa: futuros, opciones, permutas financieras, compraventa de moneda extranjera a largo plazo, etc.

- Deudas con características especiales: Deuda indexada a un índice de precios, a un tipo de cambio, etc.

- Otros pasivos financieros: deudas con terceros distintos a entidades de crédito (proveedores de inmovilizado, fianzas y depósitos recibidos, desembolsos exigidos sobre participaciones, etc.).

Se excluyen de la categoría de pasivos financieros, por presentar un tratamiento contable separado, las provisiones (norma de registro y valoración $n^{0} 15$ ), los pasivos por retribuciones a largo plazo al personal (norma de registro y valoración $n^{\circ} 16$ ) y los pasivos por impuestos diferidos (norma de registro y valoración $\mathrm{n}^{0} 12$ ).

Los pasivos financieros aparecen incluidos con más detalle, de acuerdo con su naturaleza, dentro de los subgrupos 15, 16, 17, 18, 40, 41, 46, 47, 50, 51, 52, 55 y 56 del NPGC:

15. Deudas a largo plazo con características especiales

16. Deudas a largo plazo con partes vinculadas

17. Deudas a largo plazo por préstamos recibidos, empréstitos y otros conceptos

18. Pasivos por fianzas, garantías y otros conceptos a largo plazo

40. Proveedores

41. Acreedores varios

46. Personal

47. Administraciones Públicas

50. Empréstitos, deudas con características especiales y otras emisiones análogas a corto plazo

51. Deudas a corto plazo con partes vinculadas

52. Deudas a corto plazo por préstamos recibidos y otros conceptos

55. Otras cuentas no bancarias

56. Fianzas y depósitos recibidos y constituidos a corto plazo y ajustes por periodificación 
La norma española se adapta en gran medida a la regulación internacional incluida en las normas NIC "32. Instrumentos financieros: presentación", NIC "39. Instrumentos financieros: reconocimiento y valoración" y NIIF "7. Instrumentos financieros: información a revelar". Estas normas desarrollan la clasificación recogida en el NPGC, incluyendo dos ejemplos negativos particularmente importantes de elementos patrimoniales que, si bien podrían ser considerados pasivos financieros atendiendo a su forma jurídica, no deben incluirse como tales debido a su fondo económico:

a) Las obligaciones de pago no contractuales: La ausencia de contrato entre las partes resulta incompatible con la definición de pasivo financiero. En particular, las obligaciones de pago impuestas legalmente por la Hacienda Pública (por ejemplo, el IVA) o por la Administración General de la Seguridad Social no deberían ser consideradas como pasivos financieros. Ahora bien, este desarrollo no está contemplado en el NPGC, por lo que no puede aplicarse esta excepción por el momento. El ICAC, en su caso, deberá ser el que aclare cuál es el tratamiento contable más adecuado de este tipo de obligaciones.

b) Los pagos basados en acciones: La inclusión de los pagos basados en acciones como pasivos financieros depende del tipo de cancelación pactada para la deuda: (1) Si la obligación debe o puede cancelarse entregando un número fijo de acciones propias y ésta es la práctica habitual, se trata de una partida de patrimonio neto y no de un pasivo financiero. (2) Si la obligación debe o puede cancelarse entregando un número variable de instrumentos de patrimonio (habitualmente acciones), de forma que el precio de las acciones sea una manera de evaluar la deuda, sí debe considerarse un pasivo financiero; p.e.: la empresa tiene la obligación de entregar una suma de efectivo igual al valor en bolsa de 1.000 acciones propias; la empresa ha emitido una opción cuyo valor final se pagará entregando acciones hasta alcanzar el precio de la misma.

1.2. Clasificación de los pasivos financieros según el criterio de valoración aplicable

La clasificación de los pasivos financieros según el criterio de valoración que les resulta aplicable constituye la categorización más 
importante a efectos contables, distinguiéndose tres clases principales recogidas en el apartado 3 de la norma de registro y valoración $n^{\circ} 9$ del NPGC:

1. Débitos y partidas a pagar. Incluye la mayoría de las obligaciones de pago con terceros incluidas en el pasivo de la empresa, en particular los débitos por operaciones comerciales y los débitos por operaciones no comerciales.

2. Pasivos financieros mantenidos para negociar. Recoge aquellos pasivos financieros, de importancia habitualmente residual para la empresa, que: (a) se emiten principalmente con el propósito de readquirirlos en el corto plazo, p.e. obligaciones y otros valores negociables emitidos cotizados que la empresa puede comprar en el corto plazo en función de los cambios de valor; (b) forman parte de una cartera de instrumentos financieros identificados y gestionados conjuntamente de la que existen evidencias de actuaciones recientes para obtener ganancias a corto plazo; o (c) son instrumentos financieros derivados distintos a contratos de garantía financiera o instrumentos de cobertura.

3. Otros pasivos financieros a valor razonable con cambios en la cuenta de pérdidas y ganancias. Incluye pasivos financieros que suelen ser poco significativos para la empresa, clasificados en dos categorías principales: (a) pasivos financieros híbridos, p.e. bonos referenciados al precio de unas acciones o a la evolución de un índice bursátil; y (b) otros pasivos que designe la empresa en el momento de su reconocimiento inicial al objeto de conseguir una información más relevante sobre los mismos o de evitar asimetrías contables en su reconocimiento o valoración.

Por su parte, los pasivos financieros originados como consecuencia de transferencias de activos, en los que la empresa no haya cedido ni retenido sustancialmente sus riesgos y beneficios, se valorarán de manera consistente con el activo cedido:

1. Pasivos financieros a coste amortizado (equivalente a débitos y partidas a pagar).

2. Pasivos financieros mantenidos para negociar (incluye exclusivamente los instrumentos financieros derivados distintos a contratos de garantía financiera o instrumentos de cobertura). 
La clasificación de los pasivos financieros en un grupo u otro depende tanto de su naturaleza como de la estrategia que siga la gerencia de la empresa. La decisión se tomará en el momento inicial del reconocimiento del elemento, si bien, dado el distinto impacto de cada grupo sobre la cuenta de pérdidas y ganancias, no se puede reclasificar ningún pasivo financiero desde la categoría de "pasivos financieros mantenidos para negociar" o "pasivos financieros a valor razonable" a otras categorías.

El NPGC no obliga a llevar cuentas distintas para cada categoría de pasivos financieros, pero sí a informar en la memoria de las Cuentas Anuales de los importes que integran cada uno de los grupos y de las pérdidas y ganancias derivadas de éstos.

Los débitos y partidas a pagar constituyen el núcleo principal de los pasivos financieros, por lo que se encuentran regulados de forma específica y detallada en las nuevas normas contables, siendo el objetivo básico de este estudio.

Los pasivos financieros mantenidos para negociar y los pasivos financieros a valor razonable con cambios en la cuenta de pérdidas y ganancias se contabilizan con los mismos criterios que los activos financieros mantenidos para negociar, que son objeto detallado de estudio en otro artículo de esta monografía.

\section{PAGAR}

\section{RECONOCIMIENTO Y VALORACIÓN: DÉBITOS Y PARTIDAS A}

Los débitos y partidas a pagar incluidos en el NPGC recogen dos tipos básicos de pasivos financieros con distinta incidencia contable:

- Débitos por operaciones comerciales, derivados de operaciones de tráfico habituales en la empresa. Incluye, entre otras, las deudas con proveedores, acreedores por prestación de servicios y deudas con el personal de la empresa.

- Débitos por operaciones no comerciales, con origen distinto al tráfico de la empresa y diferentes a los instrumentos derivados. Incluye, entre otras, las deudas con los proveedores de inmovilizado, fianzas y depósitos, y deudas con entidades de crédito tales como los préstamos bancarios y la parte dispuesta de las pólizas de crédito. 
El reconocimiento contable de estos pasivos financieros tendrá lugar cuando se cumplan los tres requisitos básicos incluidos en el Marco Conceptual del NPGC: cumplimiento de la definición de pasivo, probabilidad de que su cancelación requiera ceder recursos que incorporen beneficios o rendimientos económicos futuros, y estimación fiable de su valor.

Si bien la categoría de "pasivos financieros a coste amortizado" definida en el NPPYMES incluye los mismos elementos patrimoniales que los débitos y partidas a pagar del NPGC, sus criterios de valoración resultan en ocasiones más sencillos. A continuación se analiza la valoración inicial y posterior recogida en el modelo normal del nuevo Plan General de Contabilidad, incluyendo también el tratamiento simplificado para PYMEs cuando surgen diferencias entre ambas regulaciones.

\subsection{Valoración inicial}

Todos los débitos y partidas a pagar se valorarán, en el momento de su incorporación al patrimonio de la empresa, por su valor razonable. Con carácter general, este valor inicial coincidirá con el precio de la transacción o valor razonable de la contraprestación recibida, ajustada por los costes de transacción que le sean directamente atribuibles.

El valor razonable aparece definido dentro del Marco Conceptual del NPGC como aquel importe por el que puede ser intercambiado un activo o liquidado un pasivo, entre partes interesadas y debidamente informadas, que realicen una transacción en condiciones de independencia mutua, sin deducir los costes de transacción en los que pudiera incurrirse.

Así, por ejemplo, en el caso particular de un préstamo bancario concedido a la empresa, el valor razonable se calcularía como sigue:

Importe concedido

- Gastos de formalización y estudio pagados a la entidad financiera

- Impuestos pagados a la Hacienda Pública

= Valor razonable del préstamo 
Como principal excepción, el NPGC permite que los débitos por operaciones comerciales con vencimiento no superior a un año y que no tengan un tipo de interés contractual, así como los desembolsos exigidos por terceros sobre participaciones a corto plazo, puedan valorarse por su valor nominal, entendiendo por tal el valor de reembolso a pagar al vencimiento de la deuda.

Aunque no se contempla expresamente, algunos autores consideran que la redacción del NPGC indica implícitamente que, para el resto de deudas a largo plazo sin interés contractual, su valor razonable se calculará mediante la actualización de los pagos futuros, según la fórmula general:

$$
\text { Valor actual } \mathrm{l}_{0}=\sum_{j=1}^{N} \frac{\text { Desembolso }_{\mathrm{j}}}{(1+i)^{\mathrm{j}}}
$$

siendo $i$ el tipo de descuento a aplicar, que según el NPGC será un tipo de interés normal de mercado, que habitualmente será el tipo de interés explícito de operaciones similares o el tipo de interés medio de los pasivos financieros utilizados.

De esta forma, se asume que todos los débitos a largo plazo sin interés contractual explícito llevan incorporados intereses de forma implícita que deben ser objeto de reconocimiento contable.

\begin{abstract}
Tratamiento especial según el NPPYME: Los costes de transacción y las comisiones financieras por constitución de deudas de todos los débitos y partidas a pagar se pueden registrar directamente en la cuenta de pérdidas y ganancias en el momento inicial, por lo que no formarían parte del valor razonable de estos pasivos.
\end{abstract}

Se mantiene la excepción contemplada en el NPGC para la valoración inicial a valor nominal de los débitos por operaciones comerciales sin interés contractual y desembolsos exigidos por terceros sobre participaciones a corto plazo.

De acuerdo con el PGC de 1990, los pasivos financieros se valoraban inicialmente, con carácter general, por su valor de reembolso o cancelación previsto, que coincide con el valor nominal definido en el NPGC. La inclusión del valor razonable constituye una novedad fundamental de las nuevas normas que puede dar lugar a distintos problemas valorativos 


\section{y de registro contable, por lo que ha de ser objeto de atención especial por parte de los gestores.}

\section{Ejemplo 1.- Indicar el importe correspondiente a la valoración inicial de los siguientes débitos y partidas a pagar.}

Caso 1.- El día 3-5-08, la empresa "PARMA" adquiere materias primas valoradas en 80.000 (IVA 16\%), concediendo el proveedor un descuento promocional de $500 €$ reconocido en la factura, y cancelándose un anticipo concedido al mismo por importe de 20.000€. Por la deuda restante, PARMA acepta una factura a 10 meses, por lo que no se pacta ningún tipo de interés contractual y se decide aplicar la excepción del valor nominal.

Al tratarse de un débito comercial a corto plazo, recogido en la cuenta "400. Proveedores" y aplicarse el valor nominal para la valoración inicial de la deuda, ésta se reconocerá directamente por el valor de reembolso pactado, de acuerdo con el siguiente esquema:

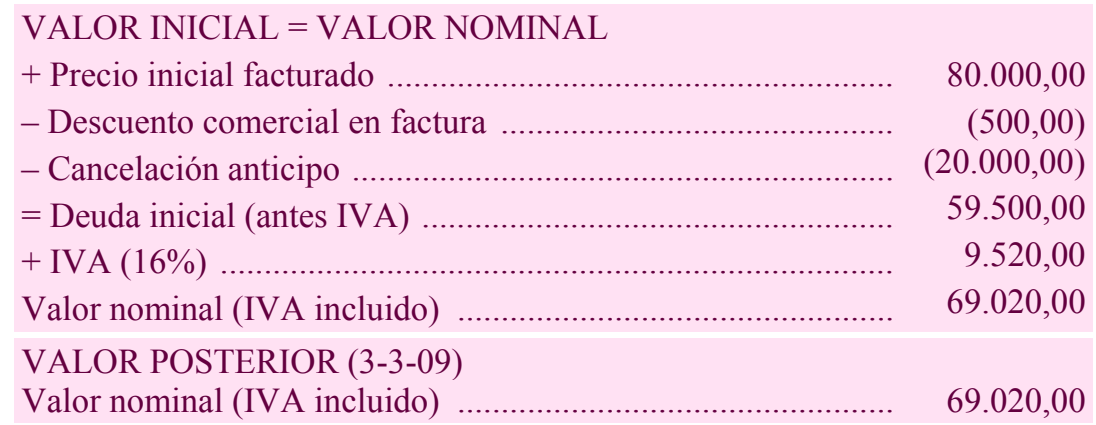

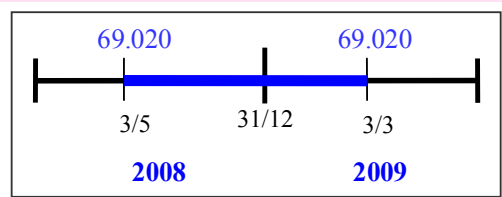

3-5-08:

$\begin{array}{cllll} & 600 \text { Compras de materias primas } & \text { a } & 407 \text { Anticipos a proveedores } & 20.000,00 \\ 9.520,00 & 472 \mathrm{HP}, \text { IVA Soportado } & \text { a } & 400 \text { Proveedores } & 69.020,00\end{array}$

Caso 2.- Considérese el mismo ejemplo de la empresa "PARMA", pero en este caso se acuerda en factura un interés simple del $6 \%$ anual, pagadero en el momento del vencimiento.

La existencia de un tipo de interés contractual (6\%) exige la valoración inicial del débito por su valor razonable, esto es, por el valor de la contraprestación recibida, sin considerar los intereses financieros, que se irán reconociendo contablemente a medida que se devenguen. De esta forma, el valor inicial del débito no se ve modificado, aunque sí lo hará su valoración posterior. 


\begin{tabular}{|c|c|}
\hline VALOR INICIAL = VALOR RAZONABLE & \\
\hline + Precio inicial facturado ................................... & $80.000,00$ \\
\hline - Descuento comercial en factura & $(500,00)$ \\
\hline - Cancelación anticipo ................... & $(20.000,00)$ \\
\hline$=$ Deuda inicial $($ antes IVA) .......... & $59.500,00$ \\
\hline+ IVA $(16 \%)$ & $9.520,00$ \\
\hline Valor nominal (IVA incluido) ...... & $69.020,00$ \\
\hline VALOR POSTERIOR (3-3-09) & \\
\hline Valor nominal (IVA incluido) ..... & $69.020,00$ \\
\hline + Intereses: $69.020 \times 6 \% \times 10 / 12$ & $3.451,00$ \\
\hline Deuda al vencimiento ..................... & $72.471,00$ \\
\hline
\end{tabular}

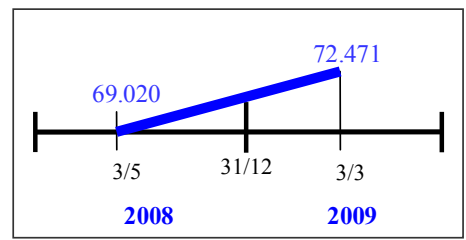

3-5-08:

$\begin{array}{rlrlr} & 600 \text { Compras de materias primas } & \text { a } & 407 \text { Anticipos a proveedores } & 20.000,00 \\ 9.520,00 & 472 \mathrm{HP}, \text { IVA Soportado } & \text { a } & 400 \text { Proveedores } & 69.020,00\end{array}$

Caso 3.- Considérese el mismo ejemplo de la empresa "PARMA", pero en este caso se acepta una factura a 14 meses, sin incluir intereses contractuales. El tipo de interés de mercado libre de riesgo es del 5\%.

En este caso se trata de un débito comercial a largo plazo, por lo que debe valorarse inicialmente a su valor razonable. Ante la ausencia de regulación del NPGC en este punto, existen dos alternativas recogidas a continuación: (a) no actualizar el valor razonable de la deuda; (b) actualizar el valor razonable de la deuda respecto a los 14 meses de su duración, de acuerdo con una tasa de descuento adecuada.

a) Si no se actualiza el valor razonable inicial de la deuda:

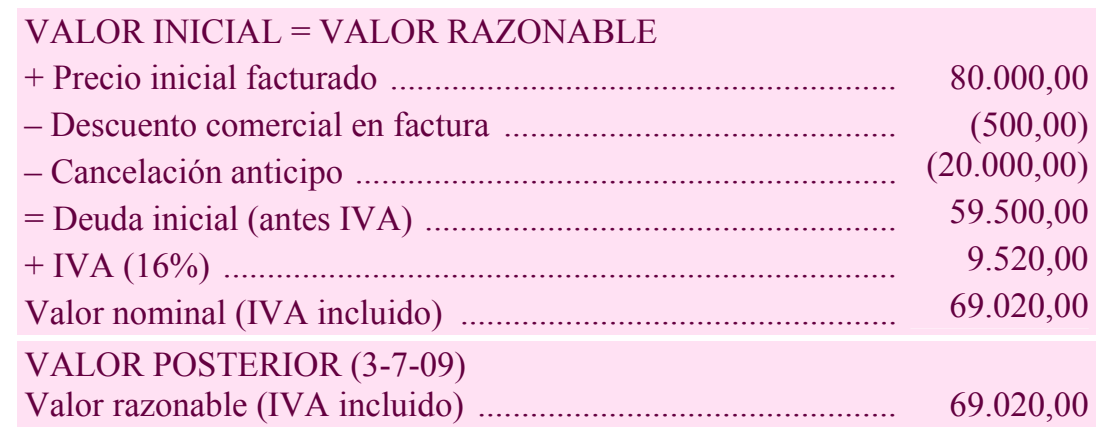




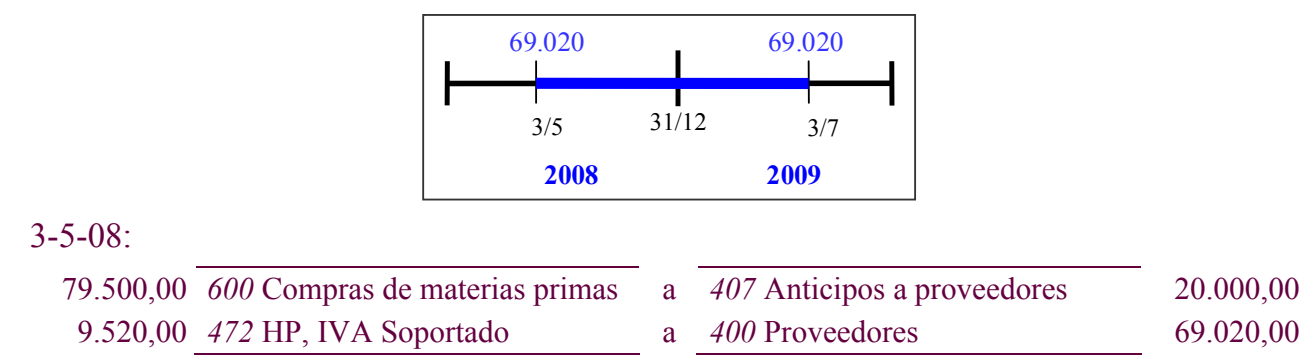

b) Si se actualiza el valor razonable inicial de la deuda (tipo de descuento: $5 \%$ ):

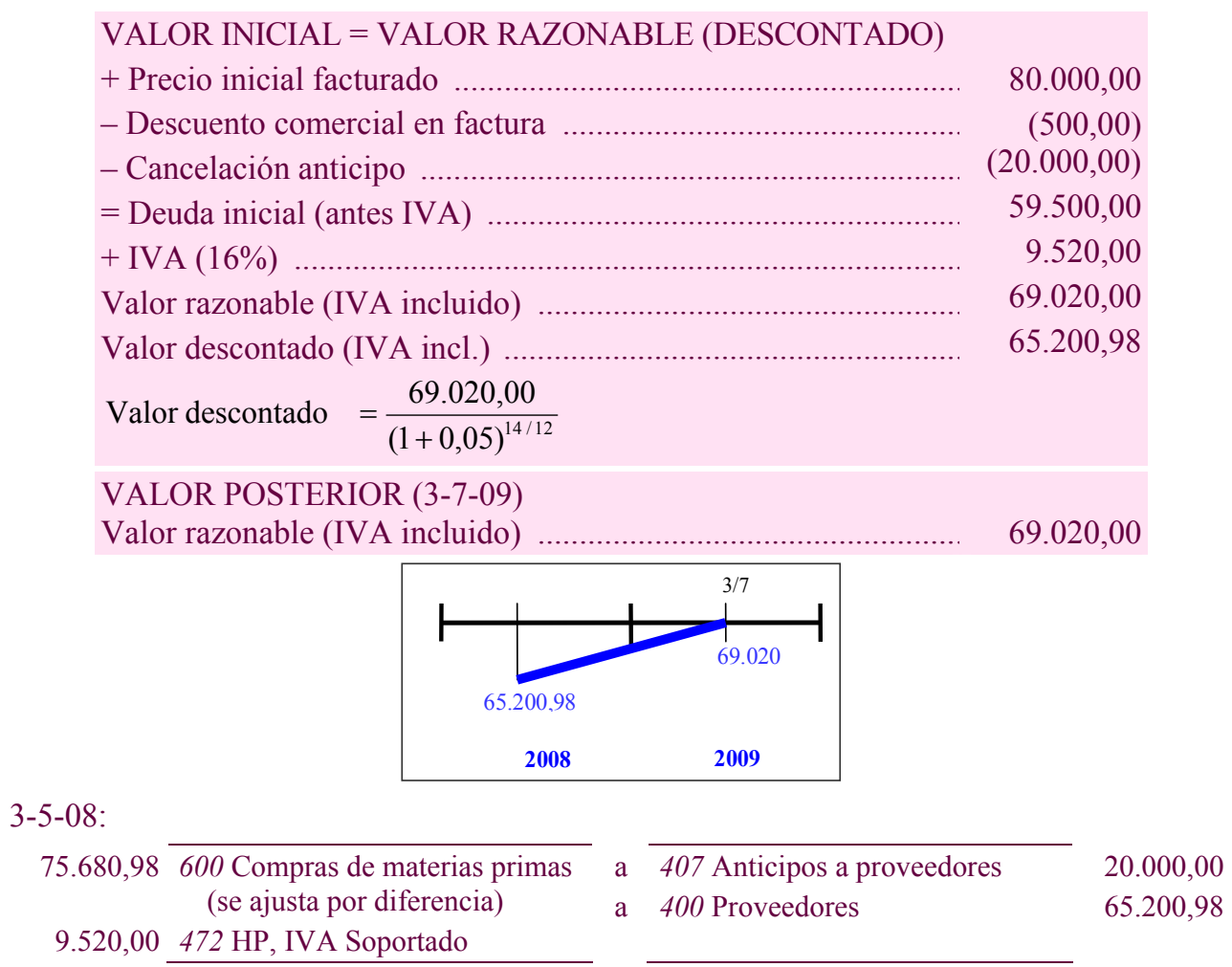

\subsection{Valoración posterior}

La valoración de los débitos y partidas a pagar, posterior a su reconocimiento inicial, deberá realizarse por su coste amortizado. El Marco Conceptual del NPGC define el coste amortizado para los pasivos financieros como el importe por el que inicialmente fue valorado el pasivo, menos los reembolsos de principal que se hubieran producido, más o menos, según proceda, la parte imputada en la cuenta de pérdidas y ganancias, 
mediante la utilización del tipo de interés efectivo, de la diferencia entre el importe inicial y el valor de reembolso en el vencimiento (intereses implícitos de la deuda).

Todos los intereses devengados se contabilizarán en la cuenta de pérdidas y ganancias aplicando el tipo de interés efectivo. De esta forma, el tipo de interés efectivo es un tipo de interés compuesto que agrupa todos los intereses financieros (explícitos y/o implícitos) devengados por la deuda, incluyendo los gastos iniciales relacionados con su formalización. El NPGC define en su Marco Conceptual el tipo de interés efectivo como:

el tipo de actualización que iguala el valor en libros de un instrumento financiero con los flujos de efectivo estimados a lo largo de la vida esperada del instrumento, a partir de sus condiciones contractuales y sin considerar las pérdidas por riesgo de crédito futuras; en su cálculo se incluirán las comisiones financieras que se carguen por adelantado en la concesión de la financiación.

No obstante, si la financiación ha sido concedida por entidades de crédito, será necesario diferenciar entre los intereses explícitos devengados y no vencidos según las cláusulas contractuales, que son objeto de registro en la cuenta "527. Intereses a c/p de deudas con entidades de crédito", y los intereses implícitos devengados y no vencidos, que incrementan el coste amortizado de la deuda.

En la práctica, el cálculo del tipo de interés efectivo de la operación financiera se realiza igualando, en el momento inicial, el valor en libros de un instrumento financiero (neto de los costes de transacción) con los flujos de efectivo estimados a lo largo de la vida esperada del instrumento:

$$
\text { Valor inicial }=\sum_{j=1}^{n} \frac{\text { Flujo efectivo }_{\mathrm{j}}}{(1+T I E)^{\mathrm{j}}}
$$

Una vez obtenido el TIE, los intereses devengados se calculan mediante la fórmula del tipo de interés compuesto:

$$
\begin{aligned}
\text { Intereses } & =\text { Coste amortizado } \times\left[(1+T I E)^{\mathrm{t}}-1\right]= \\
& =\text { Coste amortizado } \times(1+T I E)^{\mathrm{t}}-\text { Coste amortizado }
\end{aligned}
$$

Como excepción, las aportaciones recibidas como consecuencia de un contrato de cuentas en participación y similares se 
valorarán a su coste, incrementando por el beneficio o pérdida que, en su caso, deba atribuirse a los partícipes no gestores.

Asimismo, se exceptúan de la actualización, según el tipo de interés efectivo, los débitos por operaciones comerciales con vencimiento no superior a un año y que no tengan un tipo de interés contractual, así como los desembolsos exigidos por terceros sobre participaciones a corto plazo, que se continuarán valorando por su valor nominal a lo largo de toda su vida financiera. Aunque no está regulado expresamente en el NPGC, en caso que el vencimiento fuera superior al año, se procedería a la actualización de los pagos futuros a un tipo de interés normal de mercado (tipo de interés explícito de operaciones similares o tipo de interés medio de los pasivos financieros utilizados).

\begin{abstract}
Tratamiento especial según el NPPYME: Dado que los costes de transacción y las comisiones financieras por constitución de deudas se pueden registrar inicialmente en la cuenta de pérdidas y ganancias, el tipo de interés efectivo de la operación coincide con el tipo de interés explícito (contractual), facilitando enormemente la contabilización de estos pasivos financieros.
\end{abstract}

Se mantiene la excepción contemplada en el NPGC para la valoración posterior a valor nominal de los débitos por operaciones comerciales sin interés contractual y desembolsos exigidos por terceros sobre participaciones a corto plazo.

Según el PGC de 1990, la valoración posterior de los pasivos financieros coincidía, con carácter general, con su valoración inicial, siendo ambas por el valor de reembolso. De esta forma, la imputación de gastos financieros a la cuenta de pérdidas y ganancias de cada ejercicio podía tener una triple naturaleza:

1. Por los gastos de formalización de deudas: Si bien los gastos de formalización deudas se afectaban generalmente a la cuenta de pérdidas y ganancias del ejercicio a que correspondían, excepcionalmente podían distribuirse en varios ejercicios, en cuyo caso debían imputarse a resultados durante el plazo de vencimiento de las correspondientes deudas y de acuerdo con un criterio financiero (generalmente simple). 
2. Por los intereses explícitos de la deuda: El devengo de los intereses explícitos de la deuda tenía lugar aplicando un tipo de interés simple al nominal pendiente de devolución.

3. Por los intereses implícitos de la deuda: La diferencia entre el valor de reembolso final y el valor de emisión del pasivo constituyen los intereses implícitos de la deuda, que se reconocían en la cuenta de activo asimilado "gastos por intereses diferidos", siendo objeto de imputación a pérdidas y ganancias como gastos financieros durante el plazo de vencimiento de las correspondientes deudas, conforme a un criterio financiero (generalmente simple).

El NPGC introduce un tratamiento contable mucho más avanzado y complejo, de forma que el gasto financiero a reconocer en cada periodo será el que resulte de aplicar el tipo de interés efectivo de la operación (tipo de interés compuesto) al importe dispuesto en cada ejercicio incluyendo, en su caso, los gastos de transacción.

\section{Ejemplo 2.- Indicar y contabilizar la valoración posterior de los siguientes débitos y} partidas a pagar, cuya valoración inicial fue previamente calculada

Caso 1.- El día 3-5-08, la empresa "PARMA" adquiere materias primas valoradas en 80.000 (IVA 16\%), concediendo el proveedor un descuento promocional de $500 €$ reconocido en la factura, y cancelándose un anticipo concedido al mismo por importe de 20.000€. Por la deuda restante, PARMA acepta una factura a 10 meses, por lo que no se pacta ningún tipo de interés contractual y se decide aplicar la excepción del valor nominal.

\section{VALOR INICIAL $=$ VALOR NOMINAL}

Valor nominal (IVA incluido)

VALOR POSTERIOR (3-3-09)

Valor nominal (IVA incluido)

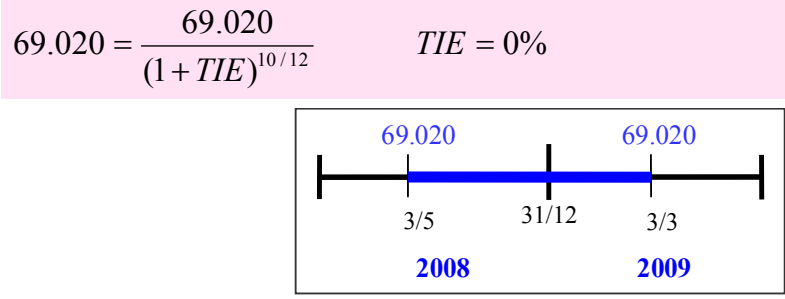

3-5-08 (Valoración inicial):
$79.500,0 0 \longdiv { 6 0 0 \text { Compras de materias primas } }$
9.520,00 472 HP, IVA Soportado
407 Anticipos a proveedores
$20.000,00$
a 400 Proveedores
$69.020,00$ 
31-12-08 (Valoración posterior):

No existen diferencias con la valoración inicial, por lo que no procede
anotación contable (no se han devengado intereses)

3-3-09 (Vencimiento):
$69.020,00$
400 Proveedores
572 Bancos, $\mathrm{c} / \mathrm{c}, €$
$69.020,00$

Caso 2.- Considérese el mismo ejemplo de la empresa "PARMA", pero en este caso se acuerda en factura un interés simple del $6 \%$ anual, pagadero en el momento del vencimiento.

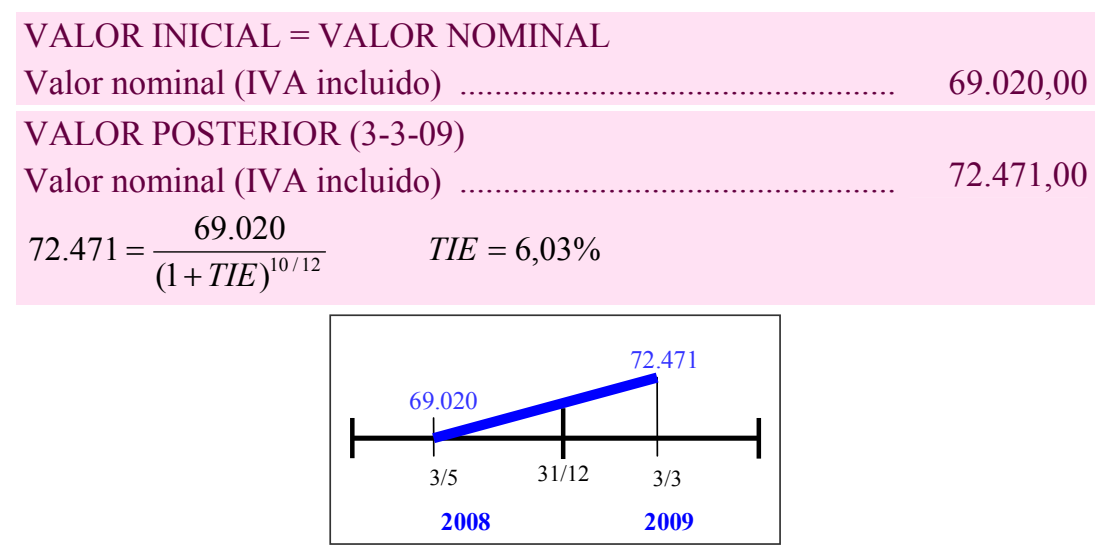

La presencia de un TIE del 6,03\% lleva a obtener la tabla de actualización de los débitos a lo largo del tiempo, que servirá de base para el cálculo del coste amortizado según su definición previa:

\begin{tabular}{|c|c|c|c|c|}
\hline Fecha & $\begin{array}{c}\text { (1) Intereses devengados } \\
\text { (TIE) }\end{array}$ & (2) Cuota / Pagos & $\begin{array}{c}\text { Amortización } \\
\text { del principal }\end{array}$ & $\begin{array}{c}\text { Coste amortizado } \\
\mathbf{( 3 )}=(\mathbf{3})_{\mathbf{1}}+\mathbf{( 1 )}-\mathbf{( 2 )}\end{array}$ \\
\hline $3-5-08$ & & & & $69.020,00$ \\
\hline $31-12-08$ & $\begin{array}{c}69.020 \times(1+0,0603)^{8 / 12}- \\
69.020=2.747,26\end{array}$ & - & - & $71.767,26$ \\
\hline $3-3-09$ & $\begin{array}{c}71.767,26 \times(1+0,0603)^{2 / 12} \\
71.767,26=703,74\end{array}$ & $72.471,00$ & $69.020,00$ & 0,00 \\
\hline
\end{tabular}

3-5-08 (Valoración inicial):

\begin{tabular}{|c|c|c|}
\hline $79.500,00$ & 600 Compras de materias primas & 407 Anticipos a proveedores \\
\hline $9.520,00$ & 472 HP, IVA Soportado & 400 Proveedores \\
\hline
\end{tabular}

31-12-08 (Valoración posterior):

$2.747,26 \quad 662$ Intereses de deudas

a 400 Proveedores

3-3-09 (Vencimiento):

\begin{tabular}{|c|c|c|c|c|}
\hline 703,74 & 662 Intereses de deudas & $\mathrm{a}$ & 400 Proveedores & 703,74 \\
\hline $2.471,00$ & 400 Proveedores & $\mathrm{a}$ & 572 Bancos, c/c, $€$ & $72.471,00$ \\
\hline
\end{tabular}


Caso 3.- Considérese el mismo ejemplo de la empresa "PARMA", pero en este caso se acepta a una factura a 14 meses, sin incluir intereses contractuales. El tipo de interés de mercado libre de riesgo es del $5 \%$.

En este caso se trata de un débito comercial a largo plazo, por lo que debe valorarse inicialmente a su valor razonable. Ante la ausencia de regulación del NPGC en este punto, existen dos alternativas recogidas a continuación: (a) no actualizar el valor razonable de la deuda; (b) actualizar el valor razonable de la deuda respecto a los 14 meses de su duración, de acuerdo con una tasa de descuento adecuada.

a) Si no se actualiza el valor razonable inicial de la deuda: La contabilización es idéntica a la del Caso 1, considerando como fecha de vencimiento el 3-7-09.

b) Si se actualiza el valor razonable inicial de la deuda (tipo de descuento 5\%):
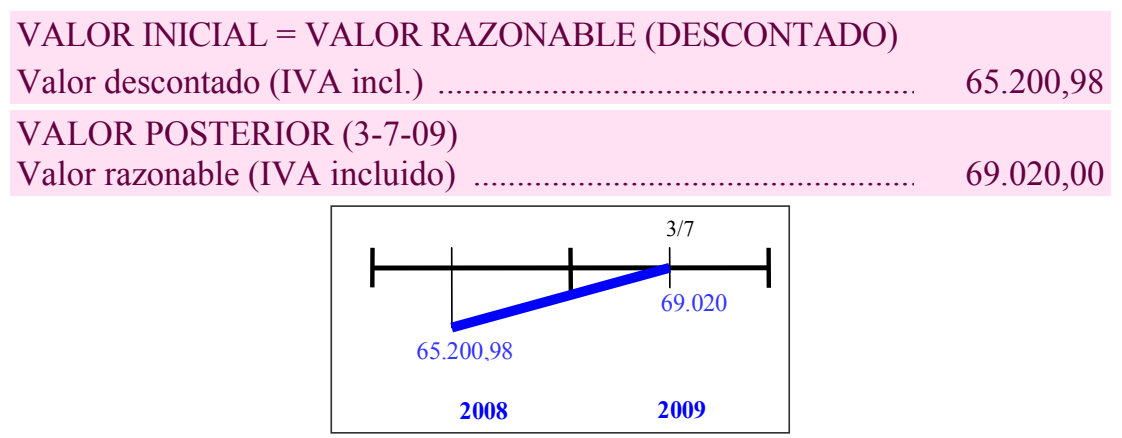

La presencia de un tipo de interés $(\mathrm{TIE}=5 \%$ ) requiere calcular la tabla de actualización de los débitos a lo largo del tiempo y el correspondiente coste amortizado:

\begin{tabular}{|c|c|c|c|c|}
\hline Fecha & $\begin{array}{c}\text { (1) Intereses devengados } \\
\text { (TIE) }\end{array}$ & (2) Cuota / Pagos & $\begin{array}{c}\text { Amortización } \\
\text { del principal }\end{array}$ & $\begin{array}{c}\text { Coste amortizado } \\
(\mathbf{3})=(3)_{-1}+(\mathbf{1})-(2)\end{array}$ \\
\hline $3-5-08$ & & & & $65.200,98$ \\
\hline $31-12-08$ & $\begin{array}{c}65.200,98 \times(1+0,05)^{8 / 12} \\
65.200,98=2.155,65\end{array}$ & - & - & $67.356,63$ \\
\hline $3-3-09$ & $\begin{array}{c}67.356,63 \times(1+0,05)^{6 / 12} \\
67.356,63=1.663,37\end{array}$ & $69.020,00$ & $65.200,98$ & 0,00 \\
\hline
\end{tabular}

3-5-08 (Valoración inicial):

\begin{tabular}{|c|c|c|c|}
\hline & & & \\
\hline $75.680,98$ & 600 Compras de materias primas & a & 407 Anticipos a proveedores \\
\hline $9.520,00$ & $\begin{array}{l}\text { (se ajusta por diferencia) } \\
472 \text { HP, IVA Soportado }\end{array}$ & $\mathrm{a}$ & 400 Proveedores \\
\hline
\end{tabular}

31-12-08 (Valoración posterior):
$2.155,65662$ Intereses de deudas
a 400 Proveedores

3-7-09 (Vencimiento):

\begin{tabular}{|c|c|c|c|}
\hline $1.663,37$ & 662 Intereses de deudas & $\mathrm{a}$ & 400 Proveedores \\
\hline $69.020,00$ & 400 Proveedores & $\mathrm{a}$ & 572 Bancos, c/c, $€$ \\
\hline
\end{tabular}




\section{PARTIDAS A PAGAR}

\section{ALGUNOS EJEMPLOS PARTICULARES DE DÉBITOS Y OTRAS}

Dada la novedad que plantea la contabilización de los débitos y partidas a pagar, a continuación se propone un conjunto de ejemplos prácticos que recoge la mayoría de la problemática que afronta las empresas respecto a estos elementos patrimoniales.

\subsection{Débitos comerciales con coste financiero explícito}

A continuación se incluye un ejemplo completo adicional referente a un débito comercial (deuda con un subcontratista) que presenta coste financiero explícito.

\section{Ejemplo 3.-}

El día 6-6-08 la empresa "OVETESA", que tiene subcontratado una parte de su proceso de fabricación a la empresa "CAMISA", recibe una factura de ésta por importe de $150.000 €$ (IVA incluido), en concepto de los servicios prestados en 2008. Dado el elevado importe, se acuerda su pago final mediante dos facturas a 6 y 12 meses, con un tipo de interés contractual del $4 \%$ simple semestral pagadero por vencido, de acuerdo con la siguiente tabla financiera:

\begin{tabular}{|c|c|c|c|}
\hline Fecha & Cuota & Amortización & Intereses \\
\hline $6-12-08$ & $79.529,41$ & $73.529,41$ & $6.000,00$ \\
\hline $6-6-09$ & $79.529,41$ & $76.470,59$ & $3.058,82$ \\
\hline Total & $159.058,82$ & $150.000,00$ & $9.058,82$ \\
\hline
\end{tabular}

El IVA de la operación (16\%) se reparte a partes iguales entre cada factura.

Caso 1.- Realizar las anotaciones contables correspondientes a los ejercicios 2008 y 2009:

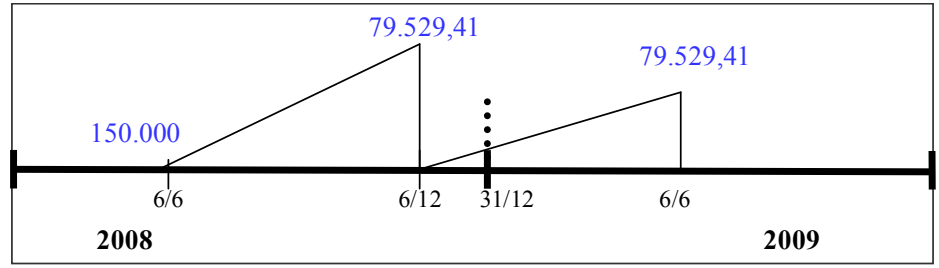

En este caso, la ausencia de gastos iniciales derivados de la operación hace que el TIE coincida con el tipo de interés contractual, y por tanto que la tabla de actualización contable coincida con la tabla de actualización financiera: 


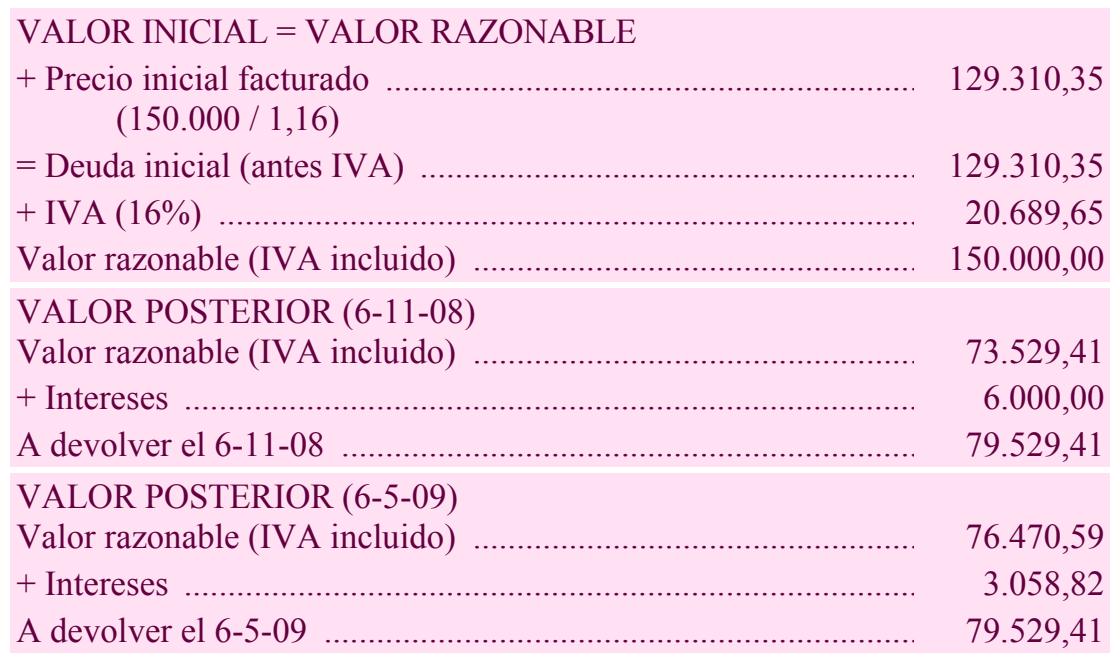

$$
\begin{gathered}
150.000=\frac{79.529,41}{(1+T I E)^{6 / 12}}+\frac{79.529,41}{(1+T I E)^{12 / 12}} \\
T I E=4,00 \% \text { semestral } \\
T I E=8,16 \% \text { anual }
\end{gathered}
$$

\begin{tabular}{|c|c|c|c|c|}
\hline Fecha & $\begin{array}{c}\text { (1) Intereses devengados } \\
\text { (TIE) }\end{array}$ & (2) Cuota / Pagos & $\begin{array}{c}\text { Amortización } \\
\text { del principal }\end{array}$ & $\begin{array}{c}\text { Coste amortizado } \\
(\mathbf{3})=(\mathbf{3})_{-1}+\mathbf{( 1 )}-\mathbf{( 2 )}\end{array}$ \\
\hline $6-6-08$ & & & & $150.000,00$ \\
\hline $6-12-08$ & $\begin{array}{c}150.000 \times(1+0,04)^{1}- \\
150.000=6.000\end{array}$ & $79.529,41$ & $73.529,41$ & $76.470,59$ \\
\hline $31-12-08$ & $\begin{array}{c}76.470,59 \times(1+0,04)^{1 / 6}- \\
76.470,59=501,51\end{array}$ & - & - & $76.972,10$ \\
\hline $6-6-09$ & $\begin{array}{c}76.972,10 \times(1+0,04)^{5 / 6}- \\
76.972,10=2.557,31\end{array}$ & $79.529,41$ & $76.470,59$ & 0,00 \\
\hline
\end{tabular}

6-6-08:

\begin{tabular}{|c|c|c|c|c|}
\hline $6.000,00$ & 662 Intereses de deudas & $\mathrm{a}$ & 400 Proveedores & $6.000,00$ \\
\hline $79.529,41$ & 400 Proveedores & $\mathrm{a}$ & 572 Bancos, c/c, $€$ & $79.529,41$ \\
\hline \multicolumn{5}{|c|}{-12-08 (Valoración posterior): } \\
\hline 501,51 & 662 Intereses de deudas & $\mathrm{a}$ & 400 Proveedores & 501,51 \\
\hline
\end{tabular}

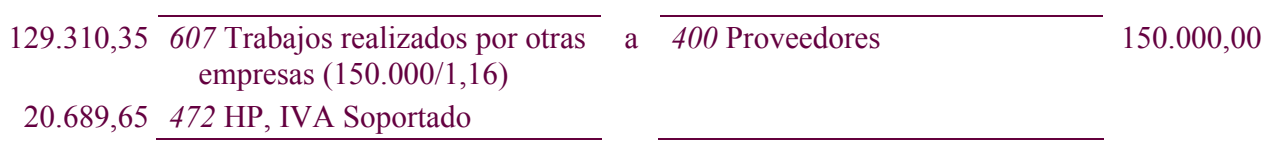

6-12-08 (Primer vencimiento):

\begin{tabular}{|c|c|c|c|c|}
\hline $2.557,31$ & 662 Intereses de deudas & $\mathrm{a}$ & 400 Proveedores & $2.557,31$ \\
\hline $79.529,41$ & 400 Proveedores & $\mathrm{a}$ & 572 Bancos, c/c, $€$ & $79.529,41$ \\
\hline
\end{tabular}

6-6-09 (Segundo vencimiento): 
Caso 2.- ¿Cómo se contabilizaría la operación si el día 5-4-09 "OVETESA" decide anticipar el pago de la deuda pendiente?

Las anotaciones contables correspondientes a las fechas 6-6-08, 6-12-08 y 31-12-08 serían idénticas a las del Caso 1.

Por su parte, el día 5/4/2009 deberían calcularse los intereses devengados desde el cierre del año 2008 hasta esta fecha (pago anticipado), de acuerdo con el tipo de interés contractual pactado (4\% simple anual), ajustando a posteriori la tabla de actualización y los intereses contables a reconocer en la cuenta "662. Intereses de deudas":

Cantidad a devolver: Principal $(76.470,59)+$ Intereses $(1.019,61)=77.490,20 €$

Intereses contractuales (simple): $I=C \times i \times t=76.470,59 \times 4 \% \times 4 / 6=1.019,61 €$

\begin{tabular}{|c|c|c|c|c|}
\hline Fecha & $\begin{array}{c}\text { (1) Intereses devengados } \\
\text { (TIE) }\end{array}$ & (2) Cuota / Pagos & $\begin{array}{c}\text { Amortización } \\
\text { del principal }\end{array}$ & $\begin{array}{c}\text { Coste amortizado } \\
\mathbf{( 3 )}=(\mathbf{3})_{-\mathbf{1}}+\mathbf{( 1 )}-\mathbf{( 2 )}\end{array}$ \\
\hline $6-6-08$ & & & & $150.000,00$ \\
\hline $6-12-08$ & $\begin{array}{c}150.000 \times(1+0,04)^{1}- \\
150.000=6.000\end{array}$ & $79.529,41$ & $73.529,41$ & $76.470,59$ \\
\hline $31-12-08$ & $\begin{array}{c}76.470,59 \times(1+0,04)^{1 / 6}- \\
76.470,59=501,51\end{array}$ & - & - & $76.972,10$ \\
\hline $5-4-09$ & $\begin{array}{c}77.490,20-76.972,10= \\
518,10\end{array}$ & $77.490,20$ & $76.470,59$ & 0,00 \\
\hline
\end{tabular}

5-4-09 (Segundo vencimiento anticipado):

\begin{tabular}{|c|c|c|c|}
\hline 518,10 & 662 Intereses de deudas & $\mathrm{a}$ & 400 Proveedores \\
\hline $77.490,20$ & 400 Proveedores & $\mathrm{a}$ & 572 Bancos, $\mathrm{c} / \mathrm{c}, €$ \\
\hline
\end{tabular}

\subsection{Débitos no comerciales: descuento de efectos}

El descuento de efectos comerciales constituye una de las operaciones financieras más habituales de las empresas, que se caracteriza por el pago anticipado de los intereses y gastos de la operación (naturaleza prepagable). La presencia de gastos iniciales hace que el TIE a efectos contables no coincida con el tipo de interés pactado con la entidad financiera, lo que dificulta su registro.

Para simplificar esta cuestión, aquéllas empresas que apliquen el NPPYMES pueden contabilizar los gastos iniciales de forma independiente, consiguiendo que el TIE contable coincida con el tipo de interés contractual, si bien debe tenerse en cuenta que:

(a) El TIE representa un tipo de interés postpagable, mientras que el tipo de interés contractual por descuento de efectos es de naturaleza prepagable, siendo la fórmula de conversión entre ambos tipos de intereses: 


$$
i_{\text {postpagable }}=\frac{i_{\text {prepagable }}}{1-i_{\text {prepagable }} \times t}
$$

(b) El TIE representa un tipo de interés compuesto y el interés contractual puede presentarse como un tipo de interés simple, siendo la fórmula de conversión entre ambos:

$$
i_{\text {compuesto }}=\sqrt[t]{\left(1 \times i_{\text {simple }}\right)^{t}+1}-1
$$

\section{Ejemplo 4. -}

El día 17-11-08 la empresa "MORISA" lleva al banco letras comerciales para su descuento siendo su valor nominal de 14.500€, cargándole el banco un interés simple del 6\% anual y comisiones varias por gestión y tenencia de $130 €$.

Supóngase que las letras vencen a los 90 días de su descuento, siendo atendidas por los clientes.

Caso 1.- Realice las anotaciones contables correspondientes a los ejercicios 2008 y 2009

\begin{tabular}{|c|c|}
\hline VALOR INICIAL = VALOR RAZONABLE & \\
\hline + Importe inicial descontado & $14.500,00$ \\
\hline - Intereses $(14.500 \times 6 \times 3 / 12)$ & $(217,50)$ \\
\hline - Comisiones varias .................. & $(130,00)$ \\
\hline Valor razonable inicial & $14.152,50$ \\
\hline $\begin{array}{l}\text { VALOR POSTERIOR (17-2-08) } \\
\text { Deuda al vencimiento }\end{array}$ & $14.500,00$ \\
\hline
\end{tabular}
según el NPGC.

$$
14.152,50=\frac{14.500}{(1+T I E)^{3 / 12}} \quad T I E=10,19 \% \text { anual }
$$

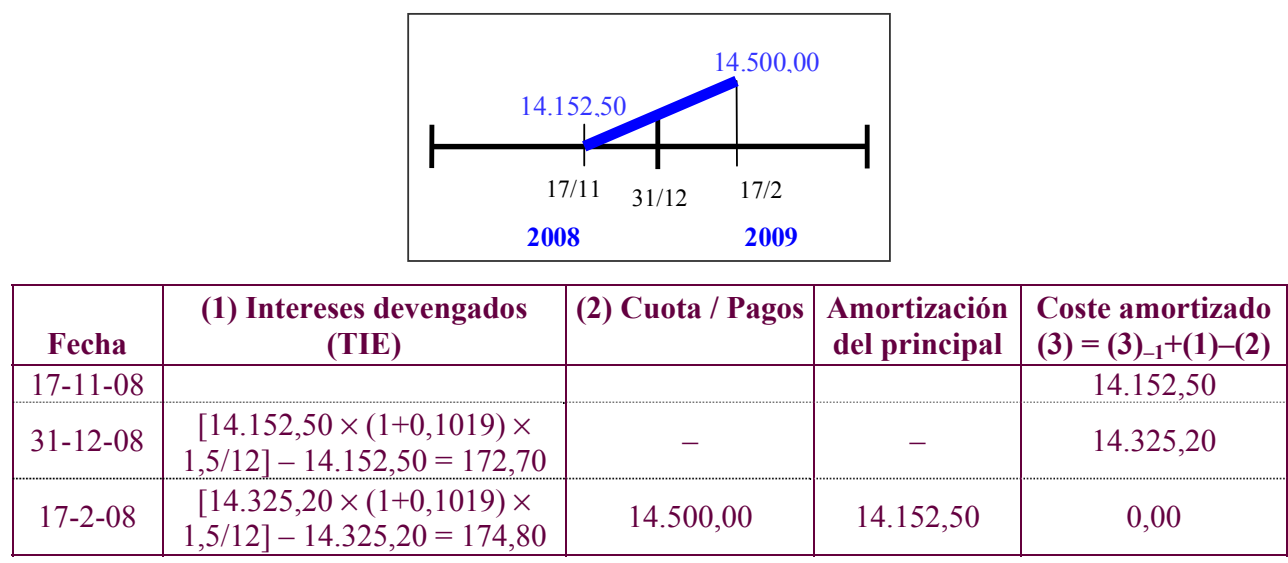


17-11-08 (Descuento):

\begin{tabular}{ll}
$14.500,00$ & $\begin{array}{c}4311 \text { Efectos comerciales } \\
\text { descontados }\end{array}$ \\
\cline { 2 - 2 } & 572 Bancos, c/c, $€$ \\
\hline
\end{tabular}

\begin{tabular}{l}
4310 Efectos comerciales en \\
cartera \\
\hline 5208 Deudas por efectos \\
comerciales descontados \\
\hline
\end{tabular}

31-12-08 (Valoración posterior):

172,70662 Intereses de deudas

17-2-09 (Vencimiento):

\begin{tabular}{rl}
174,80 & 662 Intereses de deudas \\
\cline { 2 - 2 } $14.500,00$ & $\begin{array}{r}5208 \text { Deudas por efectos } \\
\text { comerciales descontados }\end{array}$ \\
\hline
\end{tabular}

a 5208 Deudas por efectos comerciales descontados 4311 Efectos comerciales descontados

Caso 2.- Realice las anotaciones contables correspondientes a los ejercicios 2008 y 2009 según el NPPYMEs.

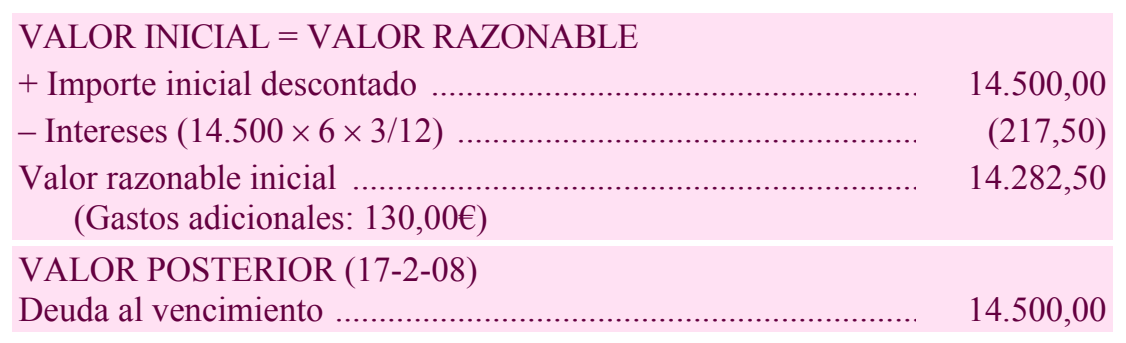

$$
14.282,50=\frac{14.500}{(1+T I E)^{3 / 12}} \quad T I E=6,23 \% \text { anual }
$$

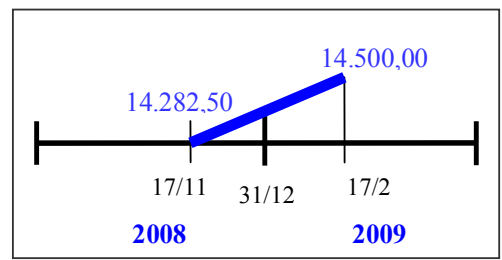

El TIE de la operación también podría haberse calculado como sigue:
a) $i_{\text {postpagable }}=\frac{0,06}{1-0,06 \times 3 / 12} \quad i_{\text {postpagable }}=0,0609=6,09 \%$
b) $i_{\text {compuesto }}(T I E)=\sqrt[3 / 12]{(1 \times 0,0609)^{3 / 12}+1}-1 \quad T I E=6,23 \%$ 


\begin{tabular}{|c|c|c|c|c|}
\hline Fecha & $\begin{array}{c}\text { (1) Intereses devengados } \\
\text { (TIE) }\end{array}$ & (2) Cuota / Pagos & $\begin{array}{c}\text { Amortización } \\
\text { del principal }\end{array}$ & $\begin{array}{c}\text { Coste amortizado } \\
(\mathbf{3})=(\mathbf{3})_{-\mathbf{1}}+\mathbf{( 1 )}-\mathbf{( 2 )}\end{array}$ \\
\hline $17-11-08$ & & & & $14.282,50$ \\
\hline $31-12-08$ & $\begin{array}{c}{[14.282,50 \times(1+0,0623) \times} \\
1,5 / 12]-14.282,50=108,34\end{array}$ & - & - & $14.390,84$ \\
\hline $17-2-08$ & $\begin{array}{c}{[14.390,84 \times(1+0,0623) \times} \\
1,5 / 12]-14.390,84=109,16\end{array}$ & $14.500,00$ & $14.282,50$ & 0,00 \\
\hline
\end{tabular}

17-11-08 (Descuento):

\begin{aligned} & $14.500,00 \begin{array}{l}4311 \text { Efectos comerciales } \\ \text { descontados }\end{array} \\ &$\cline { 2 - 2 } $14.152,50 \begin{array}{c}572 \text { Bancos, c/c, } € \\ 130,00\end{array} \\ & \begin{array}{l}\text { 626 Servicios bancarios y } \\ \text { similares }\end{array} \\ &\end{aligned}$

4310 Efectos comerciales en cartera comerciales descontados $14.500,00$

31-12-08 (Valoración posterior):

$108,34 \quad 662$ Intereses de deudas

a 5208 Deudas por efectos

comerciales descontados

17-2-09 (Vencimiento):

\begin{tabular}{rl}
109,16 & 662 Intereses de deudas \\
\cline { 2 - 2 } $14.500,00$ & $\begin{array}{r}5208 \text { Deudas por efectos } \\
\text { comerciales descontados }\end{array}$ \\
\hline
\end{tabular}

\subsection{Débitos no comerciales: préstamos bancarios con tipo} de interés fijo

Los pasivos financieros procedentes de financiación otorgada por entidades de crédito (préstamos bancarios y asimilados) constituyen una de las fuentes de recursos más habituales de las empresas. Su contabilización de acuerdo con el criterio del coste amortizado requiere calcular de forma simultánea los intereses devengados según TIE y los intereses explícitos contractuales devengados, dado que estos últimos son objeto de registro específico en la cuenta " 527 . Intereses a c/p de deudas con entidades de crédito".

\section{Ejemplo 5.-}

La sociedad "TALASA" acude el día 2-9-08 al Banco de Madrid para solicitar un préstamo de 60.000€ a devolver en tres plazos anuales de igual importe (tipo de interés nominal de la operación: $6 \%$ anual), siendo el cuadro de amortización bancario: 


\begin{tabular}{|c|c|c|c|}
\hline Fecha & Cuota & Intereses & Amortización \\
\hline $2-9-09$ & $22.446,59$ & $3.600,00$ & $18.846,59$ \\
\hline $2-9-10$ & $22.446,59$ & $2.469,20$ & $19.977,38$ \\
\hline $2-9-11$ & $22.446,59$ & $1.270,54$ & $21.176,04$ \\
\hline Total & $67.339,77$ & $7.339,77$ & $60.000,00$ \\
\hline
\end{tabular}

Los gastos iniciales derivados del estudio y formalización del préstamo ascienden a $500 €$.

Realizar las anotaciones contables correspondientes a los ejercicios 2008, 2009 y 2010.

La existencia de gastos iniciales hace que el TIE de la operación no coincida con el tipo de interés explícito del préstamo, fijado en el $6 \%$ anual, de naturaleza postpagable.

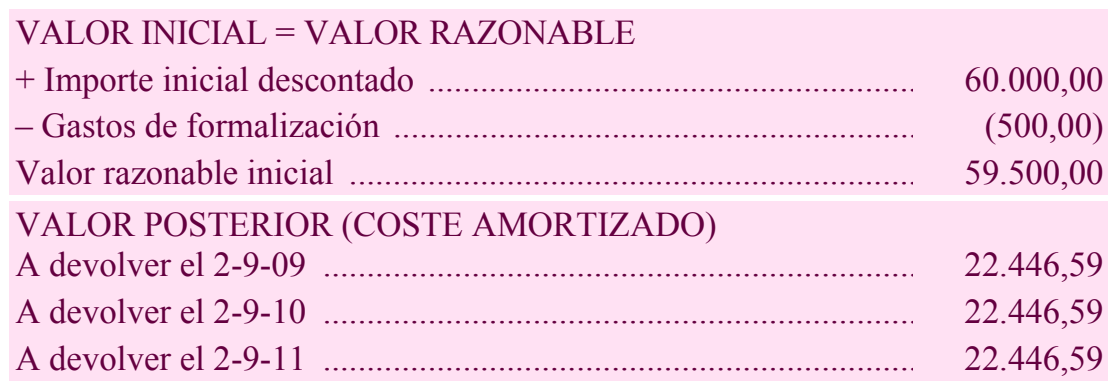

$59.500=\frac{22.446,59}{(1+T I E)^{1}}+\frac{22.446,59}{(1+T I E)^{2}}+\frac{22.446,59}{(1+T I E)^{3}}$
$T I E=6,4536 \%$ anual

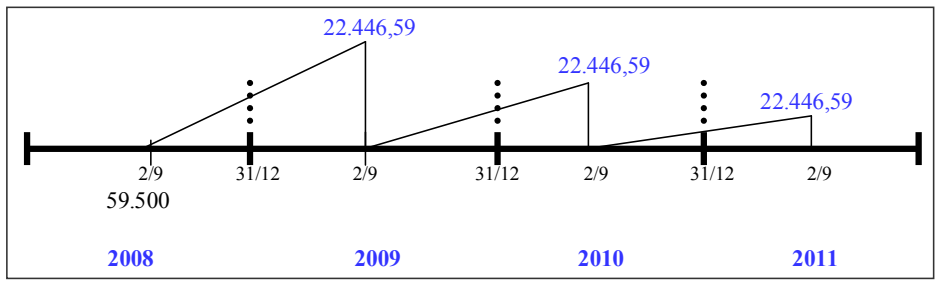

De esta forma, es necesario recalcular la tabla de amortización según criterios contables, distinguiendo entre los intereses devengados según TIE (que se utilizarán para calcular la amortización contable del principal y el coste amortizado), y los intereses explícitos contractuales devengados (que son objeto de contabilización específica en la cuenta "527. Intereses de deudas con entidades de crédito"):

\begin{tabular}{|c|c|c|c|c|c|}
\hline Fecha & $\begin{array}{c}\text { (1) Intereses } \\
\text { devengados (TIE) }\end{array}$ & $\begin{array}{c}\text { (2) Cuota } \\
\text { / Pagos }\end{array}$ & $\begin{array}{c}\text { Intereses } \\
\text { devengados } \\
\text { (explícitos) }\end{array}$ & $\begin{array}{c}\text { Amortización } \\
\text { del principal }\end{array}$ & $\begin{array}{c}\text { Coste amortizado } \\
\mathbf{( 3 ) = ( 3 ) - 1}+(\mathbf{1})-(2)\end{array}$ \\
\hline $2-9-08$ & & & & & $59.500,00$ \\
\hline $31-12-08$ & $1.253,38$ & & $1.176,77$ & & $60.753,38$ \\
\hline $2-9-09$ & $2.586,51$ & $22.446,59$ & $2.423,23$ & $18.606,70$ & $40.893,30$ \\
\hline $31-12-09$ & 861,42 & & 807,13 & & $41.754,72$ \\
\hline $2-9-10$ & $1.777,67$ & $22.446,59$ & $1.662,07$ & $19.807,50$ & $21.085,80$ \\
\hline $31-12-10$ & 444,18 & & 415,32 & & $21.529,97$ \\
\hline $2-9-11$ & 916,62 & $22.446,59$ & 855,24 & $21.085,80$ & 0,00 \\
\hline
\end{tabular}


2-9-08 (Valor inicial):

59.500,00 572 Bancos, c/c, $€$

\begin{tabular}{|c|}
\hline $\begin{array}{l}520 \text { Deudas a c/p con entidades } \\
\text { de crédito }\end{array}$ \\
\hline $\begin{array}{l}170 \text { Deudas a } 1 / p \text { con entidades } \\
\text { de crédito }\end{array}$ \\
\hline
\end{tabular}

$18.606,70$ de crédito

$40.893,30$

31-12-08 (Valoración posterior):

$1.253,38 \quad 662$ Intereses de deudas

a 527 Intereses a c/p de deudas con entidades de crédito

a 520 Deudas a c/p con entidades de crédito

2-9-09 (Pago cuota):

\subsection{6,51 662 Intereses de deudas}

$3.600,0 0 \longdiv { 5 2 7 \text { Intereses a c/p de deudas con } }$ entidades de crédito

18.846,59 520 Deudas a c/p con entidades de crédito

19.807,50 170 Deudas a 1/p con entidades de crédito

31-12-09 (Valoración posterior):

$861,42 \quad 662$ Intereses de deudas

\section{a}
520 Deudas a c/p con entidades de crédito

de credito

$19.807,50$

a 527 Intereses a c/p de deudas con entidades de crédito

a 520 Deudas a c/p con entidades de crédito

572 Bancos, $\mathrm{c} / \mathrm{c}, €$

a 520 Deudas a c/p con entidades de crédito

2-9-10 (Pago cuota):

1.777,67 662 Intereses de deudas

a 527 Intereses a c/p de deudas con entidades de crédito

a 520 Deudas a c/p con entidades

$2.469,2 0 \longdiv { 5 2 7 \text { Intereses a c/p de deudas con } }$ de crédito entidades de crédito

19.977,38 520 Deudas a c/p con entidades de crédito

21.085,80 $\overline{170 \text { Deudas a } 1 / \mathrm{p} \text { con entidades }}$

520 Deudas a c/p con entidades de crédito de crédito

31-12-10 (Valoración posterior): 444,18662 Intereses de deudas
a 527 Intereses a c/p de deudas con entidades de crédito
a 520 Deudas a c/p con entidades de crédito


2-9-11 (Pago cuota):

916,62 662 Intereses de deudas
527 Intereses a c/p de deudas con entidades de crédito

a 520 Deudas a c/p con entidades

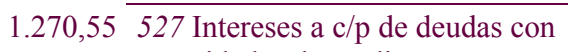
de crédito entidades de crédito

$\overline{572 \text { Bancos, c/c, } € \quad 22.446,59}$

21.176,04 520 Deudas a c/p con entidades de crédito

\subsection{Débitos no comerciales: préstamos bancarios con tipo} de interés variable

El acceso a préstamos bancarios a tipo de interés variable (por ejemplo, indexados al EURIBOR) resulta muy común para las empresas, si bien a nivel contable plantea una mayor dificultad que la financiación a tipo fijo, pues requiere el recálculo del TIE y de la tabla de actualización contable en cada fecha de revisión del tipo de interés.

\section{Ejemplo 6.-}

La sociedad "MIRESA" acude el día 1-1-08 al Banco de Palencia para solicitar un préstamo de $90.000 €$ a devolver en tres plazos anuales de igual importe pagaderos el 3112 de cada año. El tipo de interés compuesto de la operación es variable (EURIBOR+0,3), revisable anualmente.

El EURIBOR a 1-1-08 está en el 5,26\% anual, obteniéndose el siguiente cuadro de amortización bancario:

\begin{tabular}{|c|c|c|c|}
\hline Fecha & Cuota & Intereses & Amortización \\
\hline $31-12-08$ & $33.396,14$ & $5.004,00$ & $28.392,14$ \\
\hline $31-12-09$ & $33.396,14$ & $3.425,40$ & $29.970,74$ \\
\hline $31-12-10$ & $33.396,14$ & $1.759,02$ & $31.637,12$ \\
\hline Total & $100.188,42$ & $10.188,42$ & $90.000,00$ \\
\hline
\end{tabular}

Los gastos de formalización del préstamo ascienden a 1.020€. El EURIBOR a 1-1-09 es del $5,1 \%$, y a $1-1-10$ es del $5,4 \%$.

Realizar las anotaciones contables correspondientes a los ejercicios 2008, 2009 y 2010.

De nuevo, la existencia de gastos iniciales hace que el TIE de la operación no coincida con el tipo de interés explícito del préstamo (5,26\% anual postpagable). 


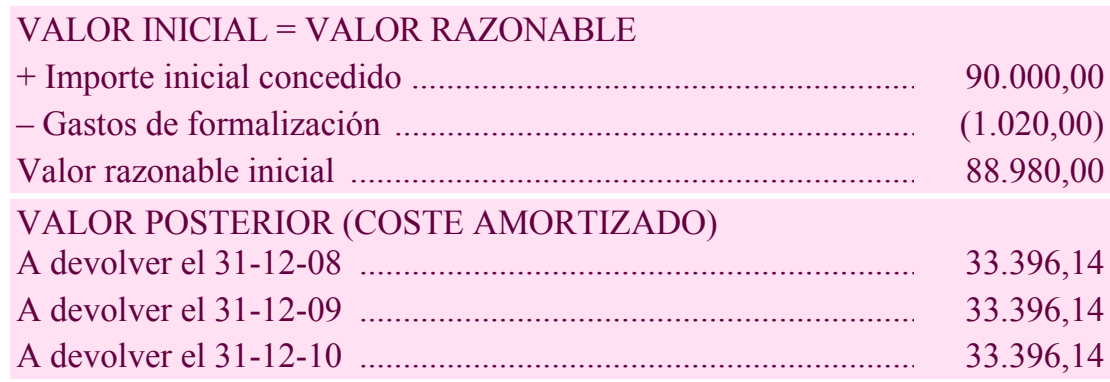
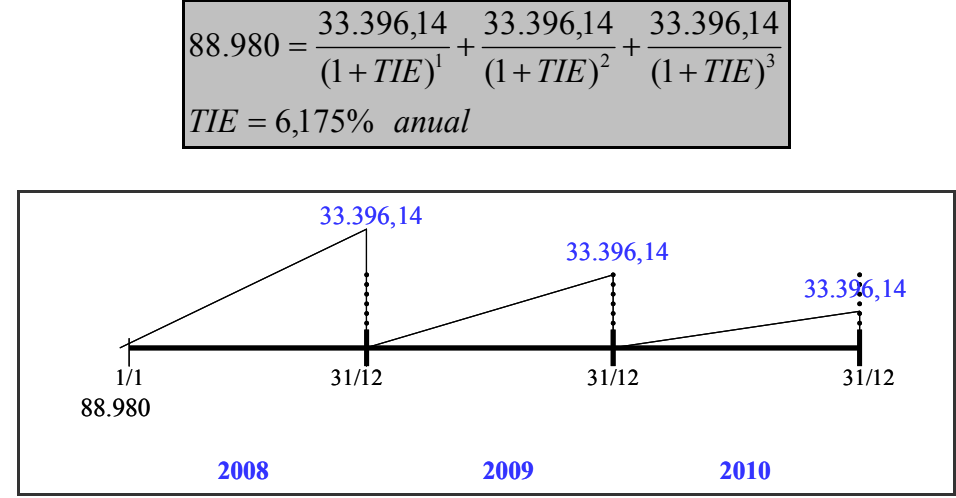

A partir del valor razonable inicial, el tipo de interés actual y las distintas cuotas previstas para la devolución del préstamo, puede recalcularse la tabla de amortización según criterios contables, distinguiendo entre los intereses devengados según TIE y los intereses explícitos contractuales devengados:

\begin{tabular}{|c|c|c|c|c|c|}
\hline Fecha & $\begin{array}{c}\text { (1) Intereses } \\
\text { devengados (TIE) }\end{array}$ & $\begin{array}{c}\text { (2) Cuota } \\
\text { / Pagos }\end{array}$ & $\begin{array}{c}\text { Intereses } \\
\text { devengados } \\
\text { (explícitos) }\end{array}$ & $\begin{array}{c}\text { Amortización } \\
\text { del principal }\end{array}$ & $\begin{array}{c}\text { Coste amortizado } \\
\text { (3)=(3) } \mathbf{- 1}+(\mathbf{1})-(2)\end{array}$ \\
\hline $1-1-08$ & & & & & $88.980,00$ \\
\hline $31-12-08$ & $5.494,53$ & $33.396,14$ & $5.004,00$ & $27.901,61$ & $61.078,39$ \\
\hline $31-12-09$ & $3.771,60$ & $33.396,14$ & $3.425,40$ & $29.624,54$ & $31.453,86$ \\
\hline $31-12-10$ & $1.942,28$ & $33.396,14$ & $1.759,02$ & $31.453,85$ & 0,00 \\
\hline
\end{tabular}

1-1-08 (Valor inicial):

88.980,00 572 Bancos, c/c, $€$
520 Deudas a c/p con entidades de crédito
a 170 Deudas a $1 / p$ con entidades de crédito

31-12-08 (Pago cuota):

\begin{tabular}{ll}
$5.494,53662$ Intereses de deudas & a $\begin{array}{c}527 \text { Intereses a c/p de deudas con } \\
\text { entidades de crédito }\end{array}$ \\
& a $\begin{array}{l}520 \text { Deudas a c/p con entidades } \\
\text { de crédito }\end{array}$ \\
\hline
\end{tabular}




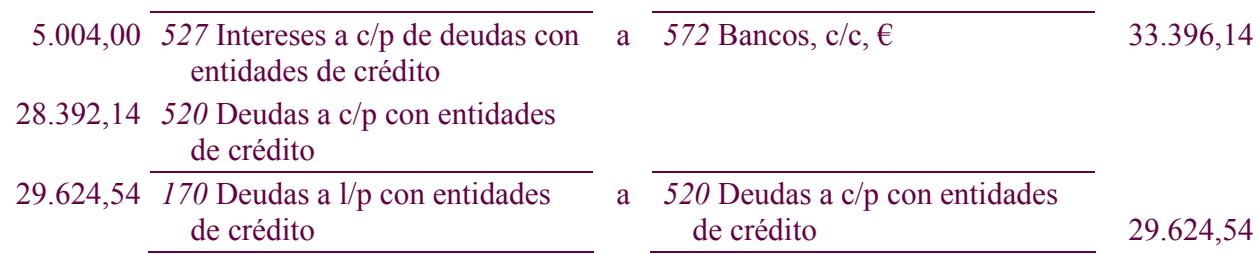

El día 1-1-09 se procede a la revisión del tipo de interés, que pasa a establecerse en el 5,1\% anual. Esta reducción del tipo de interés implica una revisión de las cuotas bancarias de amortización del préstamo, que según el método francés quedarían como sigue (esta información la proporciona la entidad de crédito):

\begin{tabular}{|c|c|c|c|}
\hline Fecha & Cuota & Intereses & Amortización \\
\hline $31-12-09$ & $33.320,91$ & $3.326,82$ & $29.994,09$ \\
\hline $31-12-10$ & $33.320,91$ & $1.707,14$ & $31.613,77$ \\
\hline Total & $66.641,82$ & $5.033,96$ & $61.607,86$ \\
\hline
\end{tabular}

Asimismo, el TIE contable debe ser recalculado, a partir del último coste amortizado (deuda pendiente con la entidad financiera: 61.078,39), y teniendo en cuenta los nuevos pagos periódicos pactados con el banco:

$$
\begin{aligned}
& 61.078,39=\frac{33 \cdot 320,91}{(1+T I E)^{1}}+\frac{33 \cdot 320,91}{(1+T I E)^{2}} \\
& T I E=6,014 \% \text { anual }
\end{aligned}
$$

Siendo la nueva tabla de actualización contable:

\begin{tabular}{|c|c|c|c|c|c|}
\hline Fecha & $\begin{array}{c}\text { (1) Intereses } \\
\text { devengados (TIE) }\end{array}$ & $\begin{array}{c}\text { (2) Cuota } \\
\text { / Pagos }\end{array}$ & $\begin{array}{c}\text { Intereses } \\
\text { devengados } \\
\text { (explícitos) }\end{array}$ & $\begin{array}{c}\text { Amortización } \\
\text { del principal }\end{array}$ & $\begin{array}{c}\text { Coste amortizado } \\
\mathbf{( 3 ) = ( 3 ) - 1 + ( 1 ) - ( 2 )}\end{array}$ \\
\hline $31-12-08$ & & & & & $61.078,39$ \\
\hline $31-12-09$ & $3.673,21$ & $33.320,91$ & $3.326,82$ & $29.647,70$ & $31.430,69$ \\
\hline $31-12-10$ & $1.890,22$ & $33.320,91$ & $1.707,14$ & $31.430,69$ & 0,00 \\
\hline
\end{tabular}

De esta forma, a fecha 1/1/2009 la nueva deuda a corto plazo se sitúa en $29.647,70 €$ (frente a los 29.624,54€ de la tabla de actualización contable original), mientras que la deuda a largo plazo pasa a ser de $31.430,69 €$ (frente a los 31.453,86 de la tabla de actualización contable original), lo que exige una reclasificación de estas partidas por la diferencia obtenida $(23,16 €)$ :

1-1-09:

\begin{tabular}{lll}
23,16 & $\begin{array}{l}170 \text { Deudas a } 1 / \mathrm{p} \text { con entidades } \\
\text { de crédito }\end{array}$ & $\begin{array}{l}520 \text { Deudas a c/p con entidades } \\
\text { de crédito }\end{array}$ \\
\hline
\end{tabular}

La siguiente cuota se paga siguiendo la mecánica contable habitual:

31-12-09 (Pago cuota):

$3.673,21662$ Intereses de deudas

a 527 Intereses a c/p de deudas con

$$
\text { entidades de crédito } \quad 3.326,82
$$

a 520 Deudas a c/p con entidades de crédito 


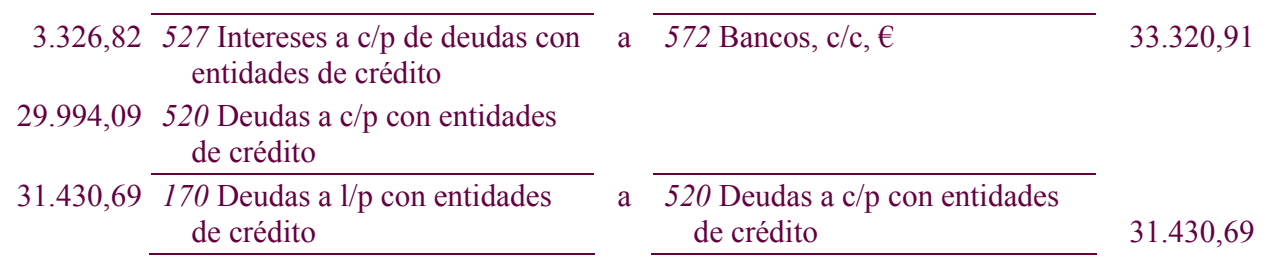

El día 1-1-10 se revisa de nuevo el tipo de interés, que pasa a establecerse en el 5,7\% anual. Este incremento del tipo de interés implica la revisión de las cuotas bancarias de amortización del préstamo, como sigue (esta información la proporciona la entidad de crédito):

\begin{tabular}{|c|c|c|c|}
\hline Fecha & Cuota & Intereses & Amortización \\
\hline $31-12-10$ & $33.415,75$ & $1.801,98$ & $31.613,77$ \\
\hline Total & $33.415,75$ & $1.801,98$ & $31.613,77$ \\
\hline
\end{tabular}

El TIE contable debe ser recalculado, a partir del último coste amortizado (deuda pendiente con la entidad financiera: $31.430,69$ ), y teniendo en cuenta los nuevos pagos periódicos pactados con el banco:

$$
\begin{aligned}
& 31.430,69=\frac{33.415,75}{(1+T I E)^{1}} \\
& T I E=6,316 \% \text { anual }
\end{aligned}
$$

Siendo la nueva tabla de actualización contable:

\begin{tabular}{|c|c|c|c|c|c|}
\hline Fecha & $\begin{array}{c}\text { (1) Intereses } \\
\text { devengados (TIE) }\end{array}$ & $\begin{array}{c}\text { (2) Cuota } \\
\text { / Pagos }\end{array}$ & $\begin{array}{c}\text { Intereses } \\
\text { devengados } \\
\text { (explícitos) }\end{array}$ & $\begin{array}{c}\text { Amortización } \\
\text { del principal }\end{array}$ & $\begin{array}{c}\text { Coste amortizado } \\
\text { (3)=(3) }+\mathbf{( 1 )}-\mathbf{( 2 )}\end{array}$ \\
\hline $31-12-09$ & & & & & $31.430,69$ \\
\hline $31-12-10$ & $1.985,06$ & $33.415,75$ & $1.801,98$ & $31.430,69$ & 0,00 \\
\hline
\end{tabular}

Para el último año, la nueva deuda a corto plazo $(31.430,69)$ coincide con la deuda reconocida en la tabla de actualización anterior, por lo que no es preciso realizar ningún asiento de reclasificación.

Finalmente, el día 31-12-10 se paga la última cuota y se cancela el préstamo:

\begin{tabular}{|c|c|c|c|c|}
\hline \multirow[t]{2}{*}{$1.985,06$} & 662 Intereses de deudas & a & $\begin{array}{l}527 \text { Intereses a c/p de deudas con } \\
\text { entidades de crédito }\end{array}$ & $1.801,98$ \\
\hline & & a & $\begin{array}{l}520 \text { Deudas a c/p con entidades } \\
\text { de crédito }\end{array}$ & 183,08 \\
\hline $1.801,98$ & $\begin{array}{l}527 \text { Intereses a c/p de deudas con } \\
\text { entidades de crédito }\end{array}$ & a & 572 Bancos, c/c, $€$ & $33.415,75$ \\
\hline $31.613,77$ & $\begin{array}{l}520 \text { Deudas a c/p con entidades } \\
\text { de crédito }\end{array}$ & & & \\
\hline $31.430,69$ & $\begin{array}{l}170 \text { Deudas a } 1 / p \text { con entidades } \\
\text { de crédito }\end{array}$ & a & $\begin{array}{l}520 \text { Deudas a c/p con entidades } \\
\text { de crédito }\end{array}$ & $31.430,69$ \\
\hline
\end{tabular}

31-12-10 (Pago cuota): 


\section{BAJA E INTERCAMBIO DE PASIVOS FINANCIEROS}

De acuerdo con la norma de registro y valoración $n^{\circ} 9$ "Instrumentos financieros" del NPGC, la empresa dará de baja un pasivo financiero cuando la obligación que éste representa se haya extinguido (por ejemplo, cancelación anticipada de un préstamo) o bien, tratándose de pasivos financieros propios, cuando la empresa los adquiera o rescate, aunque sea con la intención de recolocarlos en el futuro (por ejemplo, rescate de obligaciones en el mercado secundario).

Por su parte, el intercambio de pasivos financieros puede dar lugar a dos situaciones diferentes:

- Intercambio de pasivos financieros que NO tengan condiciones sustancialmente diferentes (ejemplo: refinanciación de deudas). En este caso no se dará de baja el pasivo financiero original, si bien el importe de las comisiones pagadas se registrará como un ajuste de su valor contable (recálculo del TIE y del coste amortizado). El coste amortizado del nuevo pasivo financiero se determinará aplicando el tipo de interés efectivo, que será aquel que iguale el valor en libros del pasivo financiero en la fecha de modificación con los flujos de efectivo a pagar según las nuevas condiciones.

- Intercambio de pasivos financieros que tengan condiciones sustancialmente diferentes (ejemplo: refinanciación de deudas). En este caso se produce una modificación sustancial de las condiciones actuales del pasivo financiero, por lo que se dará de baja el pasivo original, reconociéndose inmediatamente el nuevo pasivo financiero que surja. Los posibles gastos de cancelación y similares se reconocerán en la Cuenta de Pérdidas y Ganancias del ejercicio en que tenga lugar.

A los efectos del NPGC, se considera que las condiciones son sustancialmente diferentes si el valor actual de los flujos de efectivo del nuevo pasivo es diferente al menos en un $10 \%$ del valor de los flujos de efectivo remanentes del pasivo financiero original, actualizados ambos al TIE de este último. 


\section{Ejemplo 7.-}

La sociedad "PELUSA" tiene una deuda comercial cuyo valor en libros (coste amortizado) a la fecha de su vencimiento (1-1-08) es de 14.000€, sin coste financiero explícito. Este pasivo se intercambia por otro cuyo valor de reembolso a los dos años (31-12-09) es de 15.000€. No se sabe si las deudas tienen condiciones sustancialmente diferentes.

Realizar las anotaciones contables correspondientes al intercambio de pasivos financieros.

(1) Cálculo del TIE del conjunto de flujos de la operación:

Deuda inicial

$14.000,00$

Nueva deuda (a dos años)

(2) Comprobar que las condiciones no son sustancialmente diferentes:

$\begin{array}{lr}\text { TIE pasivo inicial ........................................................... } & 0,00 \% \\ \text { Flujos de efectivo nuevo pasivo: } 15.000 /(1+0)^{2} \ldots \ldots \ldots \ldots \ldots \ldots \ldots . & 15.000,00 \\ \text { Diferencia: } 15.000-14.000=1.000(1.000<10 \% 14.000) \ldots . . & 1.000,00\end{array}$

Se comprueba que las condiciones no son sustancialmente diferentes.

(3) Recálculo del TIE y tabla de actualización contable:

$$
\begin{aligned}
& 14.000=\frac{15.000}{(1+T I E)^{2}} \\
& T I E=3,51 \% \text { anual }
\end{aligned}
$$

\begin{tabular}{|c|c|c|c|c|}
\hline Fecha & $\begin{array}{c}\text { (1) Intereses } \\
\text { devengados (TIE) }\end{array}$ & (2) Cuota / Pagos & $\begin{array}{c}\text { Amortización } \\
\text { del principal }\end{array}$ & $\begin{array}{c}\text { Coste amortizado } \\
(\mathbf{3})=(\mathbf{3})_{-\mathbf{1}}+\mathbf{( 1 )}-\mathbf{( 2 )}\end{array}$ \\
\hline $1-1-08$ & & & & $14.000,00$ \\
\hline $31-12-08$ & $\begin{array}{c}14.000,00 \times(1+0,0351)^{1}- \\
14.000,00=491,38\end{array}$ & & $14.491,38$ \\
\hline $31-12-09$ & $\begin{array}{c}14.491,38 \times(1+0,0351)^{1}- \\
14.491,38=508,62\end{array}$ & $15.000,00$ & $14.000,00$ & 0,00 \\
\hline
\end{tabular}

\begin{tabular}{|c|c|c|c|}
\hline $491,3 8 \longdiv { 6 6 2 \text { Intereses de deudas } }$ & a & 400 Proveedores & 491,38 \\
\hline 2-09 (Vencimiento): & & & \\
\hline $508,62 \quad 662$ Intereses de deudas & $\mathrm{a}$ & 400 Proveedores & 508,62 \\
\hline $.000,00 \overline{400 \text { Proveedores }}$ & $\mathrm{a}$ & 572 Bancos, c/c, $€$ & $15.000,00$ \\
\hline
\end{tabular}

31-12-08 (Valoración posterior): 


\section{CONCLUSIONES}

El NPGC ha introducido cambios sustanciales en la contabilización de los pasivos financieros de las empresas, introduciendo tipos de interés compuesto (TIE) para el devengo de intereses y mejorando sustancialmente los cálculos actuariales para la actualización de la deuda pendiente en cada momento (concepto de coste amortizado). Estos cambios, inspirados en las Normas Internacionales de Contabilidad adoptadas por la Unión Europea (NIC 32, NIC 39 y NIIF 7), constituyen probablemente la dificultad más importante a la que se afrontan los contables ante la nueva normativa, recogiéndose en este estudio las problemáticas más habituales y las soluciones más adecuadas para cada caso.

\section{BIBLIOGRAFÍA}

Alonso Pérez, A. y R. Pousa Soto (2007) Casos prácticos del Nuevo Plan General de Contabilidad: BOE de 20 de noviembre de 2007. Madrid: Centro de Estudios Financieros.

CaÑIBAno Calvo, L. y A. MORA ENguídanos (2006) Las Normas Internacionales de Información Financiera: Análisis y Aplicación. Navarra: Thomson Civitas.

Corona Romero, E.; J. Talavero Sanguino, F. García Martínez, J. Calvo GonZález-VALINAS, A. MONZÓN SÁNCHEZ, J. VARELA COUCEIRO y R. LóPEZ GALINDO (2006) Aplicación de las Normas Internacionales de Contabilidad adoptadas por la Unión Europea (NICes). Bilbao: CISS Grupo Wolters Kluwer.

Fernández Sotero, A. y I. Carazo González (2008) Plan General de Contabilidad. Comentarios y Casos Prácticos. Madrid: Centro de Estudios Financieros.

KPMG (2008) Guía Rápida del Plan General de Contabilidad. Madrid: KPMG y AECA.

- (2008) Plan General de Contabilidad. Casos Prácticos. Madrid: KPMG y AECA.

Universidad NaCIONAL de EducaCión a Distancia (2008) PGC PYMEs. Capítulo 3. Instrumentos Financieros. Madrid: UNED.

- (2008) Casos y soluciones. Instrumentos Financieros. Madrid: UNED. 


\section{NORMATIVA REGULADORA}

INSTITUTO DE CONTABILIDAD Y AUDITORÍA DE CUENTAS (2007) [en línea] Normas Internacionales de Información Financiera aprobadas por la Unión Europea. Texto completo. NIC 32. Disponible en: http://www.icac. meh.es/reglanic.htm (fecha de consulta: 02/08/2008).

- (2007) [en línea] Normas Internacionales de Información Financiera aprobadas por la Unión Europea. Texto completo. NIC 39. Disponible en: http://www.icac. meh.es/reglanic.htm (fecha de consulta: 2-808).

- (2007) [en línea] Normas Internacionales de Información Financiera aprobadas por la Unión Europea. Texto completo. NIIF 7. Disponible en: http://www.icac. meh.es/reglanic.htm (fecha de consulta: 2-808).

REAL DECRETO 1514/2007, de 16 de Noviembre, por el que se aprueba el Plan General de Contabilidad (BOE 20-11-07). Disponible en la página Web: http://www.icac.meh.es.

ReAL DeCRETO 1515/2007, de 16 de Noviembre, por el que se aprueba el Plan General de Contabilidad para PYMEs (BOE 20-11-07). Disponible en la página Web: http://www.icac.meh.es. 